\title{
LACTOBACILOS E GERMES SINTETIZADORES DE AMILOPECTINA NA SALIVA E PLACA DENTAL
}

\section{Luiz Carlos Tovo}

Professor Adjunto do Departamento de Odontologia Preventiva e Social

\section{SINOPSE}

Foi investigado o tipo de correspondência existente entre os lactobacilos e os germes sintetizadores de amilopectina, da saliva e placa dental. Utilizon-se de 40 indivíduos, de idade entre 18 e 25 anos, divididos em quatro grupos, considerando-se os índices CPOS e a presença e ausência de cavidades de cárie, estatìsticamente diferentes.

\section{INTRODUÇ̃̃}

«Embora já esteja estabelecido que microrganismos se constituam em um elo essencial na cadeia de eventos que culminam na cárie dental, há ainda, muita conjetura a ser feita para se estabelecer a etiologia precisa desta afecção».

\section{Robert J. Fitzgerald}

A cárie dental tem sido postulada como uma alteração de origem microbiana.

I $\mathrm{n}$ ú $\mathrm{m}$ e $\mathrm{r}$ a pesquisas realizadas comprometeram grupos de microrganismos no processo de cárie, sem entretanto identificá-los, até que se pôde, experimentalmente, comprovar a participação de alguns microrga- nismos isolados, na produção de cárie em ratos e hamsters. 11, 24

Até então, lactobacilos e estreptococos, ambos acidogênicos, eram apontados como os mais prováveis microrganismos causadores da cárie dental. A sua participação sempre foi discutida e argumentada na base de uma série de observações e evidências, e hoje ainda é considerado o número de lactobacilos da saliva como um índice de atiivdade cariosa. 4, 12, 27, 29, 30

Entretanto, os trabalhos iniciais de ORLAND et alii ${ }^{24}, 1954$ e posteriormente de FITZGERALD e KEYES ${ }^{11}$, 1960, provocando cárie em animais com estreptococos, abriram novas metas no sentido de se identificar as propriedades cariogênicas dêstes microrganismos.

Trabalhos desenvolvidos na última década demonstraram que os estreptococos cariogênicos formam polissacárides extracelulares do tipo levano ou dextrano e armazenam intracelularmente, um polissacáride iodofílico tipo amilopectina ${ }^{15}$, fazendo crer que os primeiros estão relacionados com a formação de placa dental e o último desempenhando alguma atividade no processo de cárie. 16,17 
Assim, outros microrganismos que sintetizem amilopectina podem participar de alguma forma no desenvolvimento da cárie dental.

o número de lactobacilos da saliva, cultiváveis em meio seletivo, está correlacionado diretamente com a atividade cariosa em grupos de indivíduos com alta ou baixa atividade de cárie, 'ao contrário dos indivíduos que possuem moderada atividade cariosa. 30

Não existe, até o momento, investigação que correlacione o número de lactobacilos com o de germes sintetizadores de amilopectina da saliva ou de placa dental, nem o número dêstes últimos com atividade cariosa.

Os germes sintetizadores de amilopectina, inicialmente identificados em intestinos de ruminantes 14, 18, 23, estão presentes na cavidade oral, especialmente na placa dental e em pacientes com atividade de cárie, e a proporção dêstes microrganismos em relação a outros é maior em pacientes cárie-ativa do que em pacientes cárie-inativa. ${ }^{15}$

Das bactérias cultiváveis da placa dental, as que mostraram capacidade de formar o polissacáride iodofílico (amilopectina) foram os estreptococos facultativos, difteróides, fusobactérias e bacteróides, enquanto veillonelas, estreptococos anaeróbios, Vibrio sputorum e lactobacilos formaram pouco ou nada. 6

Os mesmos autores ressaltaram que de acôrdo com os achados de GIBBONS et alli.17, uma vez que a placa dental é constituída de, cêrca de $80 \%$ de bactérias cultiváveis, parece que a maioria das bactérias da placa dental possui a capacidade de produzir amilopectina.

A amilopectina armazenada no citoplasma bacteriano é visível em grânulos ao microscópio eletrônico e a quantidade dêstes grânulos é

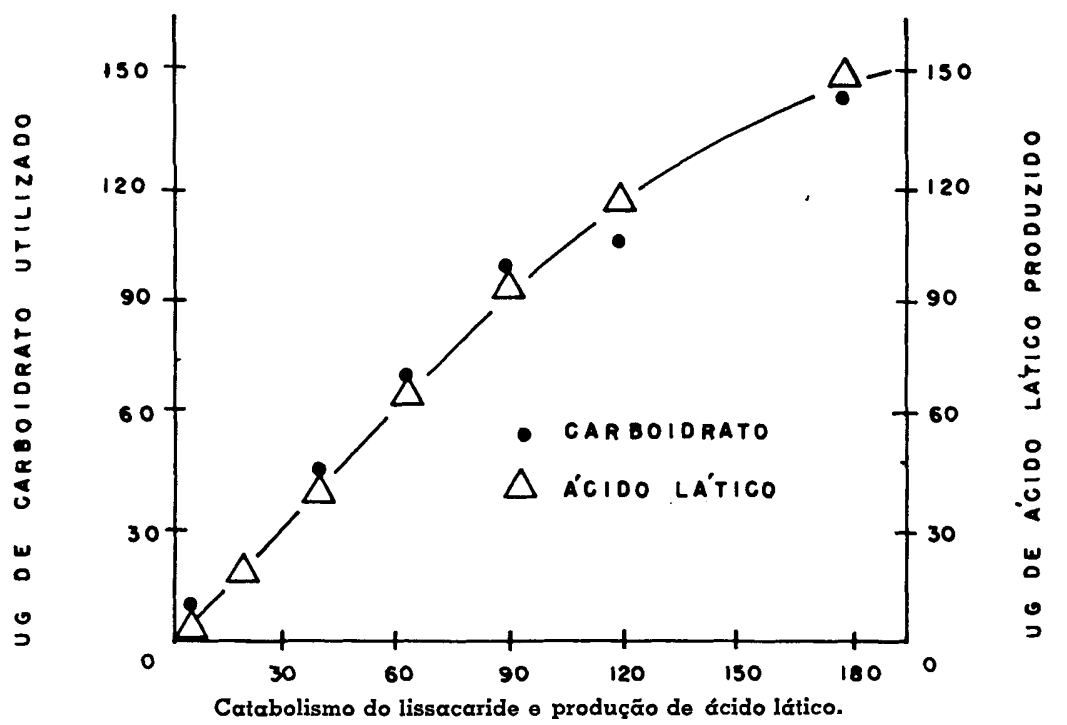

R. Fac. Odont. P. A. 
muito maior nas bactérias isoladas de placa cárie-ativa do que de bactérias de placas cárie-inativa. ${ }^{13}$

o desaparecimento dêstes grânulos, conseqüência do consumo da amilopectina, pela própria bactéria, está diretamente correlacionado com a formação de ácido lático. 16

GIBBONS e SOCRANSKY ${ }^{15}$, observaram com microrganismos iodofílicos que o conteúdo de polissacáride de amostras de estreptococos, fortemente corados pelo iodo, diminuiu ràpidamente, quando incubados em tampão e isto foi acompanhado pela, produção de ácido.

GIBBONS e KAPSIMALIS ${ }^{16}$ estudaram a sintese de amilopectina intracelular, por Streptococcus mitis, um dos microrganismos presentes na placa dental e a identificaram como um polímero composto, exclusivamente, de glicose a qual é unida em parte por ligações glicosidicas alfa 1.3 .

Os mesmos autores ${ }^{16}$ descreveram que quando êstes microrganismos foram incubados anaeròbicamente em tampão a quantidade de carboidrato endógeno catabolizado era igual à quantidade de áciddo lático produzida.

Isto sugeriu que a utilização do polissacáride endógeno seria capaz de fornecer energia de modo análogo a que é obtida por meio de fermentação de carboidratos exógenos. Além disso os microrganismos contendo pequena ou nenhuma quantidade de polissacáride, produziram uma pequena queda do $\mathrm{pH}$ durante um período de incubação de $20 \mathrm{mi}-$ nutos, na presença de fluxo constante de tampão, enquanto os que continham grande quantidade de amilopectina produziram ácido lático suficiente para baixar o $\mathrm{pH}$ aquém de 6.0 , por cêrca de 2 horas, apesar do fluxo do tampão, e até um pH 4.7 na ausência dêste fluxo. Por outro lado, esta é a faixa de pH que proporciona a descalcificação do esmalte pelo ácido lático. 16

Há uma correspondência significante, da quantidade dêstes microrganismos com atividade de cárie, pois placas de indivíduos definidos como cárie-ativa e cárie-inativa mostraram, respectivamente, $\mathrm{u} \mathrm{m}$ a média de $54,3 \%$ e $29,8 \%$ de sintetizadores cultiváveis em Agar Soy Tripticase. E ainda, microrganismos isolados que se coravam fortemente pelo iodo, incubados por 4 horas em tampão, formaram cêrca de cinco vêzes mais quantidade de ácido lático do que os corados fracamente, ou seja, foram capazes de sintetizar cinco vêzes mais, amilopectina. 15

BERMAN e GIBBONS ${ }^{6}$ demonstraram, também, que as bactérias de placas cárie-ativa são mais estáveis na produção do polissacáride do que as de placas cárie-inativa, sintetizando-o por um número maior de gerações.

Assim posta, a importância dos microrganismos sintetizadores de amilopectina, no processo de descalcificação do esmalte dental, procuramos estabelecer o tipo de correlação entre os lactobacilos e os germes sintetizadores de amilopectina da cavidade oral, realizando contagens de ambos, em meios de cultura adequados, com «inoculum» de saliva e de placa dental. 


\section{MATERIAL E MÉTODOS}

Os individuos que forneceram material para a pesquisa, foram alunos das quatro séries da Faculdade de Odontologia da U.F.R.G.S.

Examinados 130 alunos, foram selecionados 40 , com idades de 18 a 25 anos e separados em quatro grupos de 10.

Êstes grupos, estatìsticamente diferenciados pela análise de «t» no teste de «STUDENT», tinham as seguintes características:

Grupo 1 com indice CPOS de 10.1 15.7 com presença de cavidade de cárie,

Grupo 2 com índice CPOS de 6.9

a 15.2 com ausência de cavidade de cárie,

Grupo 3 com índice CPOS de 32.6 a 43.8 com presença de cavidade de cárie,

Grupo 4 com índice CPOS de 38.1 a 48.8 com ausência de cavidade cárie.

A diferenciação estatística entre os grupos permitiu confrontar as contagens de lactobacilos e de germes sintetizadores de amilopectina (SAP), entre os grupos 1 e 2, de CPOS baixos e 3 e 4 , de CPOS altos.

O exame das arcadas dentárias dos alunos foi procedido em duas etapas: exame clínico e radiográfico.

A ficha utilizada para anotar os dados dos exames, clínico e radiográfico, foi adaptada da ficha de VIEGAS-BODECKER. 31

O cálculo do índice de cárie por superfície foi de acôrdo com o mesmo autor. As anotações foram feitas sempre pela mesma pessoa, treinada para isso.

Para a collfeita de material, os 40 alunos selecionados, foram divididos em grupos de 15 e a coleta foi feita em uma mesma manhã.

Cada grupo de 15 alunos forneceu material, em duas ocasiões distantes, pois o trabalho foi feito duas vêzes para cada indivíduo. O espaço de tempo entre a primeira e a segunda colheita de material, nunca foi inferior a vinte dias.

$\mathrm{Na}$ véspera do dia da colheita, os indivíduos eram avisados pessoalmente e recebiam, por escrito, que deveriam estar, no dia seguinte, em jejum e sem escovar os dentes.

Foram coletados $5 \mathrm{ml}$ de saliva, não estimulada, em frascos contendo pérolas de vidro, esterilizados.

Após a da saliva, foi feita a colheita de material de placa denta! da seguinte forma: diversos dentes não isolados e nem secados foram raspados para formar um «pool» de material. As áreas raspadas foram selecionadas de acôrdo com as informações de MC DOUGALL $^{22}$, faces dentais proximiais, que demonstrou serem estas zonas as que possuiam um maior volume depositado de placa dental. As zonas sôbre cáries, restaurações, próteses e região cervical dos dentes foram sempre desprezadas. O instrumento utilizado para a colheita foi a cureta 13-14 do jôgo MC CALL, para trabalhos periodontais.

Após recolhidos, a saliva e o material de placa dental, seguiram-se os seguintes procedimentos: 


\section{a) Saliva}

1. Homogeneização em agitador de Kahn, por 2 minutos.

2. Diluição em solução tampão de GIBBONS 51 , até $10-6$

3. Semeadura de $0,1 \mathrm{ml}$ da solução $10^{-2} \mathrm{em}$ meio SL e incubação à $37^{\circ} \mathrm{C}$ em aerobiose; semeadura de $0,1 \mathrm{ml}$ da solução $10^{-6}$ em meio TSA e incubação à $37^{\circ} \mathrm{C}$ em ambiente de $\mathrm{N} / 95 \%$ e $\mathrm{CO}_{2} / 5 \%$ em jarra F.O.P.A. ${ }^{19}$

\section{b) Placa dental}

1. O material colhido foi pesado em papel aluminizado, prèviamente esterilizado e tarado.

2. O papel aluminizado contendo o materiai foi transferido para um gral, prèviamente esterilizado e homogeneizado com o auxílio de um pistilo e no mínimo, $1 \mathrm{ml}$ da solução tampão.

3. Obtenção da diluição $10^{-4}$ completando-se no gral com solução tampão na proporção de $1 \mathrm{mg}$ de material para $10 \mathrm{ml}$ de tampão e daí até a diluição $10-8$

4. Semeadura $0,1 \mathrm{ml}$ da solução $10^{-5}$ em meio SL e incubação à $37^{\circ} \mathrm{C}$ em aerobiose; semeadura de $0,1 \mathrm{ml}$ de cada uma das soluções $10^{-7}$ e 10-8 em meio TSA e incubação à $37^{\circ} \mathrm{C}$ em ambiente de $\mathrm{N} / 95 \%$ e $\mathrm{CO}_{2} / 5 \%$ em jarra F.O.P.A. 19

Os meios de cultura utilizados, já mencionados, foram o meio de Agar SL de ROGOSA 26 e o meio de Trypticase Soy Agar (TSA) com glicose $3 \%$ de GIBBONS. 15

A contagem das colônias de lactobacilos foi feita após três dias de incubação de acôrdo com as características descritas por diversos autores. $4,9,12,26,27$

A contagem de germes sintetizadores de amilopectina (SAP) foi realizada após cinco dias de incubação de acôrdo com a técnica descrita por GIBBONS 15

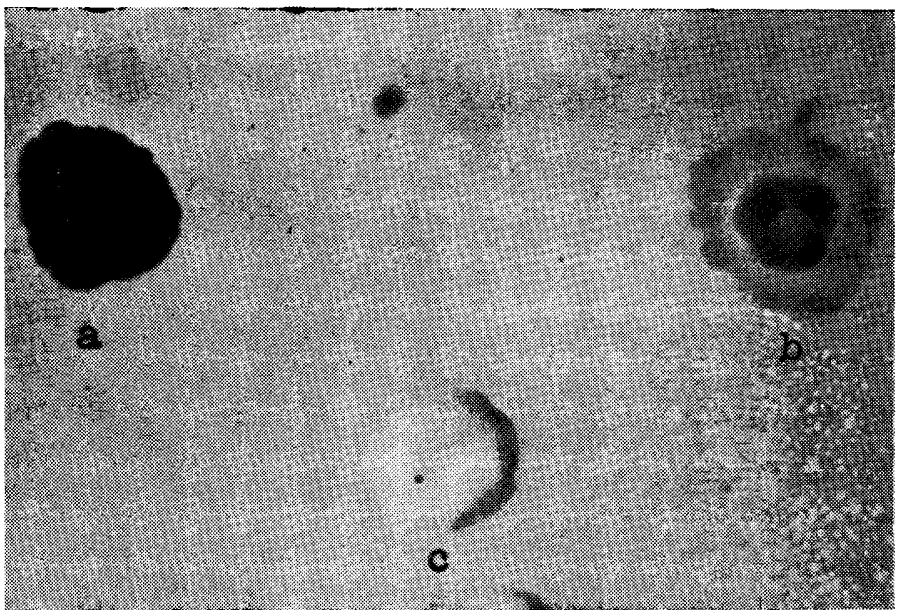

Colônias fotoarafadas em meio de TSA. com tundo brenco. coradars com solucão diluído de iodo:

a - Colônia negra, forte sintetizadora de amilopectina

b - Colônia fraca formadora de amilopectina

c - Colônia năo formdora de amilopectina.

R. Fac. Odont. P. A.

10/11: 41-57, $1968 / 1969$ 
Anotados os números de colônias de cada germe em cada ambiente estudado, foi feito o cálculo de correlação onde usamos a fórmula de $\mathrm{r}$ pela fórmula

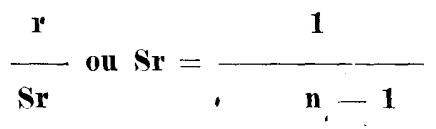

\section{RESULTADOS E DISCUSS $̃$ O}

No presente trabalho, os estudantes utilizados como fonte de material, foram preferidos porque se assemelhavam em relação às condições de higiene oral e grau de compreensão frente a uma pesquisa científica; por outro lado, é reconhecido o valor do teste de «Student» (teste de significância de «t») na análise de diferenciação, utilizado para a separação dos quatro grupos.

Trabalho anterior ${ }^{20}$, demonstrou não haver diferença, estatìsticamente significante, nas contagens de lactobacilos da saliva, quando estimulada ou não, com goma de mascar isenta de açúcar. Da mesma forma, saliva, quando diluída em água destilada ou solução tampão (semelhante à por nós utilizada, neste trabalho), semeada em meio de SL, não mostrou diferença significante, estatìsticamente. Por êste motivo, deixamos de empregar a técnica de estímulo, bem como, o diluente recomendado pelo autor do meio SL.1 ${ }^{26}$

$\mathrm{Na}$ coleta de material de placa dental, não realizamos a secagem dos dentes com ar. Isto poderia levar a imaginar que a saliva, contida no material coletado, pudesse mascarar os resultados das contagens dos microrganismos estudados. Poder-se-ia, em conseqüência, aventar como possível causa do maior número de lactobacilos da placa dental, em comparação aos da saliva, em alguns casos, o fato de transportar-se junto com o material de placa dental, alguma quantidade de saliva. Ora, se tomarmos apenas de um exemplo, como o caso do indivíduo $\mathrm{n}^{\circ} 2$ que apresenta tanto na primeira como na segunda colheitas, uma quantidade bastante maior de lactobacilos na placa dental do que na saliva, êste argumento está totalmente anulado. Senão, vejamos:

$1^{\sigma}$ colheita: diluição de placa dental $10^{-5 / \mathrm{mg}}$ apresentou contagem 7 ; diluição de saliva $10^{-2} / \mathrm{ml} \quad(\mathrm{ml}$ é 1000 vêzes mais volume que a unidade mg de placa dental) apresentou contagem 2.

$2^{a}$ colheita: diluicão de placa dental $10^{-5} / \mathrm{mg}$ apresentou contagem 270 ; diluição de saliva $10^{-2} / \mathrm{ml}$ apresentou contagem 10 .

Pode-se inferir dêstes resultados que, sendo o número de lactobacilos da saliva, em uma diluição $10^{-2} / \mathrm{ml}$, muito menor do que uma diluição de placa dental $10-5 / \mathrm{mg}$, é lógico que a alta contagem verificada no material de placa dental, não parece ser devido à contaminação do material coletado com a saliva. 
Casos semelhantes, foram apresentados, pelo menos em uma das colheitas, por mais 5 individuos. É verdade também, que nos casos de dois indivíduos (de $\mathrm{n}^{\circ} \mathrm{S}: 12$ e 17), a brusca diferenca dos resultados possa ser explicada pela colheita de material de placa dental em zona de cárie inicial de esmalte não percebida, apesar dos cuidados para evitá-la e que por sua vez, é rica em lactobacilos.

Para realizarmos a homogeneização do material, na falta de um homogeneizador de tecido ou instrumento semelhante, utilizamos um gral e um pistilo. Pensamos ter obtido com isto, uma completa destruição ou dissolução dos germes do material coletado que continha bactérias, o que comprovamos com esfregaços corados pelo Gram. Ainda que tal não fôsse atingido, a repetição da mesma técnica em todos os casos, permitia a comparação dos resultados obtidos.

Das diluições utilizadas para a semeadura, duas não foram encontradas na revisão da literatura: saliva no meio TSA e placa dental no meio SL. Escolhemos as, diluições 10-6 de saliva, para o meio TSA e 10-5 de placa dental, para o meio SL, baseados nos resultados de provas pilôto, que nos indicaram ser aquelas que forneciam um número, fàcilmente contável, de colônias. Isto foi comprovado, à medida que desenvolvemos o trabalho. As dilui- ções da saliva, para semear em meio SL $\left(10^{-2}\right)$ e da placa dental, para semear em meio TSA $\left(10^{-7}\right.$ e $\left.10^{-8}\right)$, corresponderam às utilizadas nos trabalhos de ROGOSA 26 e GIBBONS. 15

A incubação do meio TSA foi à temperatura de $37^{\circ} \mathrm{C}$. GIBBONS ${ }^{15}$ utilizou em seus estudos, a temperatura de $35^{\circ} \mathrm{C}$, para a observação de germes sintetizadores de amilopectina, todavia, as provas-pilôto, demonstraram também, não haver diferença de resultados à $35^{\circ} \mathrm{C}$ ou $37^{\circ} \mathrm{C}$.

Êste mesmo autor utilizou um ambiente de $\mathrm{H}_{2} / 95 \%$ e $\mathrm{CO}_{2} / 5 \%$. A troca de $\mathrm{H}_{2}$ por $\mathrm{N}_{2}$, foi pelo motivo de a mistura com aquêle gás, ser altamente explosiva. Comunicação pessoal de Wilson Chagas de Araújo ${ }^{1}$ orientou-nos no sentido da utilização de $\mathrm{N}_{2}$, com os mesmos resultados, em relação ao crescinento de germes sintetizadores de amilopectina.

As correlações e correspondência, de acôrdo com os resultados das TABELAS 1,2 e 3 e a freqüência, de acôrdo com a TABELA 4, serão analisadas da seguinte forma:

1) Lactobacilos em placa dental e saliva

2) Germes SAP em placa dental e saliva

3) Lactobacilos e germes SAP em placa dental e lactobacilos e germes SAP em saliva. 


\section{TABELA 1}

TOTAIS E MEDIAS DAS CONTAGENS DE LACTOBACILOS E GERMES SAP FORTES ENCONTRADOS EM SALIVA E PLACA DENTAL

\begin{tabular}{|c|c|c|c|c|c|c|c|}
\hline \multirow[t]{2}{*}{ Grupo } & \multirow[t]{2}{*}{ cPos } & \multirow{2}{*}{$\begin{array}{c}\begin{array}{c}\text { Lesão } \\
\text { cariosa }\end{array} \\
\cdot\end{array}$} & \multirow{2}{*}{$\begin{array}{l}\text { No indi- } \\
\text { víduos }\end{array}$} & \multicolumn{2}{|c|}{ Lactobacilos } & \multicolumn{2}{|c|}{ Germes SAP } \\
\hline & & & & $\begin{array}{c}\text { Placa } \\
10^{-5}\end{array}$ & $\underset{10^{-2}}{\text { Saliva }}$ & $\underset{10^{-7}}{\text { Placa }}$ & $\underset{10^{-6}}{\text { Saliva }}$ \\
\hline $\begin{array}{l}1 \\
2 \\
3 \\
4\end{array}$ & $\begin{array}{r}10.1-15.7 \\
6.9-15.2 \\
32.6-43.8 \\
38.1-48.8\end{array}$ & $\begin{array}{c}\text { Presente } \\
\text { Ausente } \\
\text { Presente } \\
\text { Ausente }\end{array}$ & $\begin{array}{l}10 \\
10 \\
10 \\
10\end{array}$ & $\begin{array}{r}149 \\
49 \\
249 \\
83\end{array}$ & $\begin{array}{r}82 \\
174 \\
771 \\
1.101\end{array}$ & $\begin{array}{l}68 \\
62 \\
71 \\
56\end{array}$ & $\begin{array}{l}28 \\
15 \\
23 \\
22\end{array}$ \\
\hline $\begin{array}{l}\text { TOTAI } \\
\text { MÉDIA }\end{array}$ & GRUPO & & $\begin{array}{l}40 \\
10\end{array}$ & $\begin{array}{l}530 \\
132\end{array}$ & $\begin{array}{r}2.128 \\
532\end{array}$ & $\begin{array}{r}257 \\
64\end{array}$ & $\begin{array}{l}88 \\
22\end{array}$ \\
\hline
\end{tabular}

\section{TABELA 2}

INDICES DE CORRELAÇÃO ENTRE OS LACTOBACILOS E GERMES SAP FORTES CONTADOS EM SALIVA E PLACA DENTAL

\begin{tabular}{c|c|c|c|c}
\hline Grupo & $\begin{array}{c}\text { Lactobacilos } \\
\text { da Placa den- } \\
\text { tal e Saliva }\end{array}$ & $\begin{array}{c}\text { Germes SAP da } \\
\text { Placa Dental } \\
\text { e Saliva }\end{array}$ & $\begin{array}{c}\text { Lactobacilos e } \\
\text { Germes SAP da } \\
\text { Placa Dental }\end{array}$ & $\begin{array}{c}\text { Lactobacilos e } \\
\text { Germes SAP da } \\
\text { Saliva }\end{array}$ \\
\hline & & & & $-0,11$ \\
2 & 0,88 & $-0,50$ & 0,61 & 0,22 \\
3 & 0,30 & $-0,38$ & 0,05 & $-0,08$ \\
4 & 0,25 & $-0,19$ & $-0,22$ & $-0,28$ \\
\hline
\end{tabular}

R, Fac, Odont, P. A. 
TABELA 3

TOTAIS DAS CONTAGENS DE LACTOBACILOS E GERMES SAP FORTES DOS GRUP.OS COM BAIXO E ALTO ÍNDICE CPOS

\begin{tabular}{|c|c|c|c|}
\hline & Grupos & CPOS & Total \\
\hline $\begin{array}{l}\text { Lactobacilos da } \\
\text { Saliva }\end{array}$ & $\begin{array}{l}1+2 \\
3+4\end{array}$ & $\begin{array}{l}\text { Baixo } \\
\text { Alto }\end{array}$ & $\begin{array}{r}256 \\
1.872\end{array}$ \\
\hline $\begin{array}{l}\text { Lactobacilos da } \\
\text { Placa }\end{array}$ & $\begin{array}{l}1+2 \\
3+4\end{array}$ & $\begin{array}{l}\text { Baixo } \\
\text { Alto }\end{array}$ & $\begin{array}{l}198 \\
332\end{array}$ \\
\hline $\begin{array}{l}\text { Germes SAP da } \\
\text { Saliva }\end{array}$ & $\begin{array}{l}1+2 \\
3+4\end{array}$ & $\begin{array}{l}\text { Baixo } \\
\text { Alto }\end{array}$ & $\begin{array}{l}43 \\
45\end{array}$ \\
\hline $\begin{array}{l}\text { Germes SAP da } \\
\text { Placa Dental }\end{array}$ & $\begin{array}{l}1+2 \\
3+4\end{array}$ & $\begin{array}{l}\text { Baixo } \\
\text { Alto }\end{array}$ & $\begin{array}{l}130 \\
127\end{array}$ \\
\hline
\end{tabular}

TABELA 4

FREQUUENCIA DE LACTOBACILOS E GERMES SAP FORTES NOS 40 INDIVÍDUOS EXAMINADOS

\begin{tabular}{|c|c|c|c|c|}
\hline & \multicolumn{2}{|c|}{ Lactobacilos } & \multirow{2}{*}{$\begin{array}{c}\text { Germe } \\
\times\end{array}$} & \multirow{2}{*}{$\underset{\%}{\mathbf{S A P}}$} \\
\hline & $\mathrm{N}^{\circ}$ & $\%$ & & \\
\hline Saliva & 29 & 72,5 & 21 & 53 \\
\hline Placa Dental & 14 & 35 & 26 & 65 \\
\hline
\end{tabular}

R. Fac. Odont. P. A. 


\section{1 - hactobacilos em PLaca DENTAL E SALIVA}

Os indices de correlação calculados com os números das contagens de lactobacilos e placa dental, em cada grupo em separado, como mostra a TBELA 2, foram todos positivos.

Estes resultados comparados com a Tabela de significância de «r», ao nível de 0,01 de probabilidade, mostram que apenas no grupo $1(0,88)$, a correlação entre os lactobacilos da placa dental e da saliva, é significante.

A correlação significante do grupo de indice CPOS de 10.1 a 15.7 , poderia ser julgada, como conseqüência da repetição de quatro resultados iguais a zero; dois outros, um, quase zero e outro, próximo a zero, valôres êstes que representam $60 \%$ dos dados a serem correlacionados. lógico, que com seis valôres quase idênticos, em um total de dez, possa admitir-se que «r» tenda a ser significante.

Poderia então, surgir a objeção, de estabelecer-se uma falsa correlação. Estariam, realmente ausentes, os lactobacilos? Seriam, de baixa concentração, as diluições usadas na semeadura para os lactobacilos da placa dental e da saliva?

A diluição de saliva usada, foi $10^{-2} / \mathrm{ml}$, recomendada por ROGO$\mathrm{SA}^{26}$ para a contagem de lactobacilos. Ora, se a contagem com esta diluição, várias vêzes, em ocasiões distintas no mesmo indivíduo, foi zero, é porque realmente não existiam lactobacilos na saliva. Mesmo assim, consideramos esta correlação prejudicada.

As diluições usadas, de placa dental, foram $10^{-5} / \mathrm{mg}$ (que consta na Tabela 1) e $10-4 / \mathrm{mg}$. Em todos os casos em que não houve crescimento à diluição $10^{-5} \mathrm{mg}$, também não o houve à $10^{-4} \mathrm{mg}$. Esta diluição foi utilizada, também, com o propósito de comprovar os resultados de $10^{-5} / \mathrm{mg}$.

Por outro lado, se considerarmos que em quatro casos houve ausência de crescimento de lactobacilos da saliva e que, a saliva, depois da lingua (BARBOSA e ARAÚJO ${ }^{3}$, 1968) é onde mais se contram estes microrganismos e ainda, que nestes casos houve também ausência de crescimento correspondente de lactobacilos de placa dental, parece-nos lógico inferir que, realmente, lactobacilos não existiam nem em saliva nem em placa dental dêstes indivíduos.

Nos demais grupos, em que não houve significância ao nivel de 0,01 de probabilidade, segundo PEAR$\mathrm{CE}^{25}$, não significa que não haja associação de qualquer espécie, entre as variáveis estudadas, mas, sòmente que esta correlação não está na forma de uma direção comum, isto é, ao aumento ou diminuição, do número de lactobacilos da placa dental, não houve correspondência na saliva e vice-versa.

Por outro lado, foi confirmada a correspondência entre os números totais das contagens de lactobacilos da saliva e os índices CPOS (ver TABELA 1).

Nos grupos 1 e 2, de índises 
CPOS mais baixos, a contagem total atingiu a 256 colônias, com a dilução $10^{-2} / \mathrm{ml}$, como mostra a TABELA 3. Nos grupos 3 e 4, de índices CPOS mais elevatos, a contagem total atingiu a 1.872 colônias, com a diluição $10^{-2} / \mathrm{ml}$. Êstes resultados, em última análise, estão de acôrdo com os achados, por SNYDER ${ }^{30}$ e SCHNEIDER SANTOS ${ }^{29}$, entre outros autores.

$\mathrm{Na}$ placa dental ocorreu correspondência entre os lactobacilos e índice CPOS (ver TABELA 3) de forma semelhante à que ocorreu na saliva, pois nos grupos 1 e 2 com índices CPOS baixos, a contagem total foi de 198 colônias à diluição $10^{-5} / \mathrm{ml}$ enquanto nos grupos de índices CPOS altos a contagem atingiu 332 colônias em idêntica diluição.

Êstes resultados, correspondência de lactobacilos da saliva e índice CPOS era de se esperar, enquanto na placa dental, a correspondência verificada merece especulação, pois, talvez os lactobacilos encontrados em placas dentais em maior número nos individuos com indices CPOS altos, o foram, por estarem as placas dentais coletadas situadas sôbre cáries de esmalte em início de desenvolvimento o que teria passado desapercebidos pelo autor. Mesmo assim a presença de lactobacilos na placa dental contraria totalmente os resultados de GIBBONS et alii ${ }^{17}$, 1964 e parcialmente os de BARBOSA e ARAÚJ'O ${ }^{3}$, 1968. Os primeiros, não encontraram lactobacilos na placa dental, talvez por terem usado meio de agar sangue e incubação em $\mathrm{H}_{2} / 95 \%$ e $\mathrm{CO}_{2} / 5 \%$, enquan- to os últimos usando o meio SL, o mesmo usado por nós, encontraram lactobacilos em sòmente 3 de 21 pacientes, ao passo que nós encontramos em 14 de 40 pacientes, sendo 8 dos 14, portadores de cárie, clìnicamente constatável.

Por outro lado, nossos resultados foram de acôrdo com os de SCHAMSCHULA e BARMES ${ }^{28}, 1970$ que encontraram lactobacilos em placa dental de $27,4 \%$ de 54 indivíduos indígenas de Papua, Nova Guinea.

Examinando a freqüência de ocorrências de lactobacilos, na saliva e na placa dental, dos 40 indivíduos com os quais trabalhamos (ver TABELA 4) encontramos uma diferença notável de $72,5 \%$ na saliva para $35 \%$ na placa dental, ou seja, os lactobacilos são encontrados $\mathrm{em} \mathrm{um}$ número duas vêzes maior de pessoas na saliva do que na placa dental.

\section{2 - GERMES SAP EM PLACA DENTAL E SALIVA}

Os índices de correlação entre os germes SAP da placa dental e da saliva foram, positivo no grupo $1 \mathrm{e}$ negativo nos demais (TABELA 2).

Comparados, êstes valôres, com a tabela de significância de «r», ao nível de 0,01 de probabilidade, não houve correspondência, estatìsticamente significante entre os germes SAP da saliva e de placa dental.

Assim como ocorreu com os lactobacilos da placa dental, baseados no que diz PEARCE25, encontramos uma associação entre os números totais dêstes microrganismos da saliva e cs índices CPOS, como mos- 
tra a TABELA 3 , onde o número maior de germes foi nos grupos com CPOS mais altos e vice-versa.

Entretanto, o número de germes SAP de placa dental, não correspondeu ao CPOS, mas se considerarmos os grupos pela presenca, apenas de cavidade de cárie, o número mais elevado de germes SAP, 139 correspondeu aos, grupos 1 e 3 com presença de cárie, enquanto o menor número, 118, ocorreu nos grupos sem cavidade de cárie, 2 e 4.

A presença de germes SAP, tanto nos grupos com cavidade de cárie como nos sem cavidade de cárie é perfeitamente compreensivel, pois não significa que a presença de germes SAP deva ser sòmente em grupos cárie-ativa. Ocorrem também em placas de indivíduos cárie-inativa como descrevem BERMAN5, BERMAN e GIBBONS 6 e GIBBONS e SOCRANSKY ${ }^{15}$, variando apenas na estabilidade de produção do polissacáride endocelular, pois os últimos autores ${ }^{15}$ encontraram uma média de $54,3 \%$ de SAP cultiváveis da microbiota da placa dental enquanto nós encontramos cêrca de $65 \%$.

Por outro lado, como se observa na TABELA 1, o número de germes SAP foi muitíssimo maior na placa dental do que na saliva, embora aí também seja avultado.

Tal resultado parece mostrar a preferência dêstes microrganismos pela placa dental em relação à saliva, o que é lógico pois a saliva, segundo MCDONALD ${ }^{21}, 1962$ não pode ser considerada mais do que um veículo que comportaria, no caso, os germes SAP desalojados da placa dental. Enquanto isso, a placa den- tal, como um nicho de condições que permite o crescimento dêstes microrganismos, dentre ela e a saliva, parece ser o habitat predileto para os microrganismos sintetizadores de amilopectina.

A média dos números totais de germes SAP da placa dental é semelhante aos resultados encontrados por BRITO et alii. ${ }^{7}$

Considerando-se a frequiência de ocorrências de germes SAP, na saliva e na placa dental (TABELA 4) notamos que cêrca de $35 \%$ dos indivíduos revelaram não possui-los na placa dental e $46,3 \%$, na saliva.

Comparando-se as frequências de ocorrências dos lactobacilos e germes SAP, na saliva e placa dental, podemos notar a predileção dos germes SAP pela placa dental e dos lactobacilos pela saliva, mas não significando isso que a saliva, como já frisamos, seja o «habitat» ou nicho para qualquer dos microrganismos estudados.

\section{3 - LACTOBACILOS E GERMES SAP EM PLACA DENTAL E LACTOBACILOS E GERMES SAP EM SALIVA}

Os índices de correlação entre os lactobacilos e germes SAP, da placa dental, foram insignificantes quando levados à tabela de significância de «r» ao nível de 0,01 de probabilidade, da mesma forma que os níveis de correlação entre os mesmos germes da saliva.

Analisando-se os totais das médias das contagens, dos quatro grupos estudados, na TABELA 1, en- 
contramos um predomínio nítido dos germes SAP sôbre os lactobacilos, tanto na placa dental como na saliva. Isto parece tamb̧ém ser lógico, pois a maioria dos germes SAP, é estreptococo, e êstes são os microrganismos de maior incidência em qualquer área ou nicho da cavidade bucal. 8

A análise dos totais das médias das contagens dos grupos, com e sem cavidades de cárie mostra: nos grupos, com cavidade de cárie houve, na placa dental, maior número de lactobacilos, 399, e de germes SAP, 139, do que nos grupos sem cavidades de cárie com 132 e 118, respectivamente.

Na saliva, houve maior número de germes SAP, 51, nos grupos com cavidade de cárie do que nos grupos sem cavidade de cárie, 37. Entretanto, o mesmo não ocorreu com os lactobacilos, o que possa talvez ser explicado pelos altos números das contagens que apresentaram dois indivíduos.

Com relação aos resultados dos germes SAP houve a confirmação dos de GIBBONS e SOCRANSKY ${ }^{15}$ que encontraram em placas dentais de indivíduos com cárie-ativa de $48 \%$ a $64 \%$ e de cárie-inativa de $14 \%$ a $47 \%$ de cultiváveis.

Os valôres de «r», encontrados em todos os casos estudados de correlação, com exceção de um (grupo 1, $r=0,88)$, não foram significantes, estatìsticamente e além disso, demonstraram regular e baixo graus de correspondência. Poderíamos, como faz BANCROFT ${ }^{2}$, formular uma questão: são estas correlações, de regular e baixo graus, verdadeiramente, correlações reais?

Para esta análise, foi necessário o cálculo do valor do êrro padrão de «r», $S_{r}$, obtido pela fórmula 1

$$
S_{r}=\frac{}{\sqrt{n-1}} \cdot \text { A significação }
$$

de $\ll r »$ foi verificada, divindo-se seu valor pelo de seu êrro padrão e o valor final encontrado, interpretado na tabela de significância de «r» (FISHER e YATES). 10

Excetuando-se o caso de correlação significante, os demais apresen-

\begin{tabular}{|c|c|c|c|c|}
\hline Grupo & 1 & 2 & 3 & 4 \\
\hline $\begin{array}{l}\text { Lactobacilos da placa } \\
\text { dental e saliva }\end{array}$ & $\mathrm{x}$ & $\mathbf{0 , 8 9}$ & 0,75 & 0,90 \\
\hline $\begin{array}{l}\text { Germes SAP fortes da } \\
\text { placa dental e saliva }\end{array}$ & 1,66 & 0,51 & 1,15 & 0,57 \\
\hline $\begin{array}{l}\text { Lactobacilos e germes } \\
\text { SAP fortes da placa dental }\end{array}$ & 0,33 & 1,84 & 0,01 & 0,66 \\
\hline $\begin{array}{l}\text { Lactobcilos e germes } \\
\text { SAP fortes da saliva } \\
\end{array}$ & 0,66 & 0,02 & $\mathbf{0 , 8 4}$ & 0,72 \\
\hline
\end{tabular}
taram os seguintes resultados:

R. Fac. Odont. P. A. 
Os valôres em ‘negrito são de correlações reais, ao nível de 0,01 de probabilidade e significam que, um número maior de experiências de contagens de microrganismos, não alteraria o valor de «r», mantendose êste, sem significância. Considerados, ao nivel de 0,05 de probabilidade, os valôres encontrados, no grupo 3 , referente aos lactobacilos da placa dental e saliva, bem como, no grupo 4, referente aos lactobacilos e germes SAP fortes da saliva, observase que tais valôres são significantes, situando-se bem próximos ao de 0,01 , tornando-os pràticamente reais.

Nestas condições, foi uniforme o resultado com as correlações dos lactobacilos da placa dental e da saliva, mostrando-as reais.

Quanto às demais correlações, houve-as reais (sublinhadas) e discrepantes, estas em número pouco maior (5 para 7 , respectivamente). Tais resultados, sugerem e recomendam a realização de novas experiências, no sentido de confirmar, modificar ou estabelecer correlações reais e significantes.

\section{CONCLUSÕES}

Da análise de nossos resultados podemos concluir que:

1) Em relação à distribuição de Lactobacillus na saliva e na placa dental de grupos humanos com e sem lesão de cárie (medida pelo índice CPOS), nas condiçes experi- mentais empregadas, concluimos que, dada à falta de correlação estatìsticamente significante, outras fontes microbianąs devem contribuir com lactobacilos para a saliva.

2) Em relação à distribuição de Germes sintetizadores de amilopectina na saliva e na placa dental de grupos humanos com e sem lesão de cárie (medida pelo índice CPOS), nas condições expermientais empregadas, concluimos, que há maior percentagem e freqüência nas placas dentais de indivíduos cárie-ativa, e que parece ser êste nicho o contribuinte para a presença dêstes microrganismos na saliva.

3) Como não houve correlação estatìsticamente significante entre o número de Lactobacillus e Germes sintetizadores de amilopectina na placa dental, não será esta capacidade fisiológica de certos microrganismos da placa dental a condição necessária e suficiente para garantir - maior número de lactobacilos na placa dental, inúmeras vêzes mostrado pelos pesquisadores.

\section{SYNOPSIS}

Correlation between Lactobacilli and Iodophilic Polissacharide Storage type Amilopectin Organisms from saliva and dental plaque was investigated in 40 humans with age between 18 and 25 years old, divided in four groups by DMFS index. 


\section{REFERENCIAS BIBLIOGRÁFICAS}

1. ARAÚJo, W. C. - Comunicação pessoal.

2. BANCROFT, ${ }^{\prime}$ Huldah - Introducción a la bioestatística. Buenos Aires, Eudeba, 1960. 500 p. (p. 179-188).

3. BARBOSA, M. T. \& ARAÚJO, W. C. - Ocorrência de Lactobacillus nos nichos microbianos da cavidade da bôca. Arquivos do Centro de Estudos da Faculdade de Odontologia, Belo Horizonte, 5:115-122, 1968.

4. BECKS, $\mathrm{H}$. et alii - Carbohydrate restriction in the prevention of dental caries using L. acidophilus count as one index. The Journal of the California State Dental Association, San Francisco, $26: 53-58,1950$.

5. BERMAN, K. S. - Production of glycogen-amilopectin-like polysaccharides by plaque microorganisms. International Association for Dental Research, Chicago, p. 103, 1963.

6. BERMAN, K. S. \& GIBBONS, R. J. - Iodophilic polysaccharide synthesis by human and rodent oral bacteria. Archives of Oral Biology, Oxford, 11:533-542, 1966.

7. BRITTO, J. D. et alii. - Estudos sôbre a influência da escovação dental na microbiota da placa dental de crianças (no prelo).

8. BURNETT, G. W. \& SCHERP, H. W. - Oral microbiology and infectious disease. 2.ed. Baltimore, Williams \& Wilkins, 1967, 1003 p. (p. 273-327).

9. COHEN, A. H. - A comparision of the Snyder colorimetric test with Lactobacillus count using Rogosa medium. Journal of Dental Research, Chicago, 36:375-381, 1957.

10. FISHER, R. A. \& YATES, F. - Statistical tables for biological, agricultural and medical research. 5.ed. London, Oliver and Boyd, 1957,138 p. .

11. FITZGERALD, R. J. \& KEYES, P. H. Demonstration of the etiologic role of streptococci in experimental caries in the hamster. Journal of American Dental Association, Chicago, 61:9-19, 1960.

11. FOSDICK, L. S. - The role of sugar in dental caries. The Journal of the California State Dental Association, San Francisco, 26: 19-27, 1950.

13. FRANK, R. M. \& BRENDEL, A. - A ultrastructure of the approximal dental plaque and the underlying normal and carious enamel. Archives of Oral Biology, Oxford, 11:883-912, 1966.

14. GIBbons, R. J. - Polysaccharide production by bovine rumen bacteria, Maryland, University of Maryland, College Park, 1956 (Tese), $46 \mathrm{p}$. 
15. GIBBONS, R. J. \& SOCRANSKY, S. S. - Intracellular polysaccharide storage by organisms in dental plaques. Archives of Oral Biology, Oxford, $7: 73-80,1962$.

16. GIBBONS, R. J. \& KAPSIMALIS, B. - Synthesis of intracellular iodophilic polysaccharide by Streptococcus mitis. Archives of Oral Biology, Oxford, 8:319-329, 1963.

17. GIBBONS, R. J. et alii - Studies of the predominant cultivable microbiota of dental plaque. Archives of Oral Biology, Oxford, 9: 365-370, 1964.

18. HENnEBer'a, W. apud GIBBons, R. J. - Polysaccharide production by bovine rumen bacteria, Maryland, University of Maryland, College Park, 1956 (Tese), 46 p.

19. LOURo $F^{\circ}$, P. P. et alii - Jarra F. O. P. A. de anaerobiose. Arquivos do Centro de Estudos da Faculdade de Odontologia, Belo Horizonte, 2:215-227, 1965.

20. LOURO $\mathbf{F}^{\circ}, \mathrm{P}$. P. et alii - Contagem de lactobacilos; análise de dois fatôres: diluente e estímulo. Arquivos do Centro de Estudos da Faculdade de Odontologia, Belo Horizonte, 4:39-55, 1967.

21. MACDONALD, J. B. - Microbiology of Caries. In: Reidar F. Sognnaes Chemistry and Prevention of Dental Caries. Springfield, C. Thomas, 1962 (23 p.).

22. MCDOUGALL, W. A. - Studies on the dental plaque. I. The histology of the dental plaque and its attachment. Australian Dental Journal, Sydney, 8:261-273, 1963.

23. MOIR, R. J'. \& MASSON, M. S., apud GIBBONS, R. J. - Polysaccharide production by bovine rumen bacteria, Maryland, University of Maryland, College Park, 1956 (Tese), $46 \mathrm{p}$.

24. ORLAND et alii - Use of the germ-free animal technic in the study of experimental dental caries; basic observations on rats reared free of all micro-organims. Journal of Dental Research, Chicago, $33: 147-174,1954$.

25. PEARCE, S. C. - Biological statistics; an introduction. New York, McGraw-Hill Book Company, 1965, 212 p. (p. 150).

26. ROGOSA, M. et alii - A selective medium for the isolation and enumeration of oral lactobacilli. Journal of Dental Research, Chicago 30:682-689, 1951.

27. ROVELSTAD, G. H. et alii - Caries susceptibility tests, hyaluronidase activity of saliva and dental caries experience. Journal of Dental Research, Chicago, 37:306-311, 1958.

28. SCHAMSCHULA, R. G. \& BARMES, D. E. - The lactobacillus flora of saliva and plaque in primitive peoples in Papua - New Guinea. Australian Dental Journal, Sydney. 15:28-34, 1940. 
29. SChNEIDER SANTOS, J. O. - Distribuição de espécies de Lactobacillus na saliva; estudo procedido em dois grupos de crianças com índices CPOS diferentes. Pôrto Alegre, Globo, 1961, (Tese), $79 \mathrm{p}$.

30. SNYDER, M. L. et alii - Evaluation of laboratory tests for estimation of caries activity. Journal of American Dental Association, Chicago, 65:31-45, 1962.

31. Viegas, A. R. - Indice de cárie. Revista da Associação Paulista de Cirurgiões-Dentistas, São Paulo, 5:13-23, 1952. 